\title{
GEOMETRY DEPENDENCE ON THE BEHAVIOUR OF MASONRY CLAY BLOCKS AT HIGH TEMPERATURES
}

\author{
ALANA P. C. QUISPE ${ }^{1}$, RENE Q. RODRÍGUEZ ${ }^{2}$ AND ROGÉRIO C. A. LIMA ${ }^{3}$ \\ ${ }^{1}$ Department of Civil Engineering, Federal University of Santa Maria \\ Santa Maria, RS, Brazil \\ alanacostaquispe@gmail.com \\ ${ }^{2}$ Department of Mechanical Engineering, Federal University of Santa Maria \\ Santa Maria, RS, Brazil \\ rene.rodriguez@ufsm.br \\ ${ }^{3}$ Department of Civil Engineering, Federal University of Santa Maria \\ Santa Maria, RS, Brazil \\ rogerio@ufsm.br
}

Key words: Masonry structures, Thermal behaviour, Fire situation, Numerical model

\begin{abstract}
The development of different constructive techniques is somehow conditioned to the investment in scientific research, aiming at comprehend the behaviour of materials; not only as individuals, but also as a whole compound. One area that has growth, for its importance in structural integrity analysis, is the analysis of masonry structures in fire situations. However, there exists an inherent difficulty on performing real standard tests under fire situations. The present work has as its main objective the study of the thermal behaviour of clay blocks at high temperatures, having the geometry of internal cavities as the main reference parameter. For this purpose, four different geometric configurations were analyzed. The thermal analysis was accomplished by using the commercial software ABAQUS. It was considered radiation, convection and conduction as heat transfer mechanisms. Radiation and convection was accounted for heat transfer between fire and the fire-exposed face of the wall, and between the wall and the ambient. As a simplification, it was considered air as solid for the cavity representation. Thus, heat conduction was considered within the internal cavities. The numerical simulations were purely thermal, aiming at analyzing the dependence of the internal geometry of the cavities. Numerical results show that thermal behavior not only depends on the empty spaces, but also on their distribution along the block interior.
\end{abstract}

\section{INTRODUCTION}

Structural verification has a huge importance in structural design, this importance is magnified in a situation such as a in a fire. Reasons for this importance are diverse, some of them can be mentioned as follows:

- To minimize the risk to human life; 
- To avoid premature structural failure, allowing users to escape and to apply correct proceedings in a fire situation [7];

- To guarantee permeability and thermal behavior of the components in sharing areas of buildings.

In Brazil, experimental investigations for determining fire resistance in structural components should be conducted following the normative NBR 5628:2001 [1]. In order to a masonry wall be considered fire resistant, it should fulfill three main criteria: Mechanical Resistance (R), Thermal Behaviour (T), and Permeability (P). This criteria are explained in details in the following section.

Experimental and semi-empirical studies have diverse limitations, as they are usually conservative and highly expensive. A complementary alternative is the use of advanced numerical models, in which several system configuration can be analyzed [5], [6], [9], [10].

Regarding the development of numerical models related to high temperatures, it is important to comprehend that thermochemical and thermophysical reactions are considered in an indirect manner, by relating to them thermophysical properties, that should vary as a function of temperature [3]. No less important are the correct consideration of heat transfer mechanisms that are fundamental in systems in which the temperature is different from the ambient temperature. Basically, three heat mechanism are herewith considered: conduction, convection and radiation.

Based on the above-mentioned considerations, the present work has as its main objective to analyze the thermal behaviour of blocks with different geometries. Results should be a good starting point for an initial study for evaluating fire resistance in more complex systems, such as prisms or masonry walls.
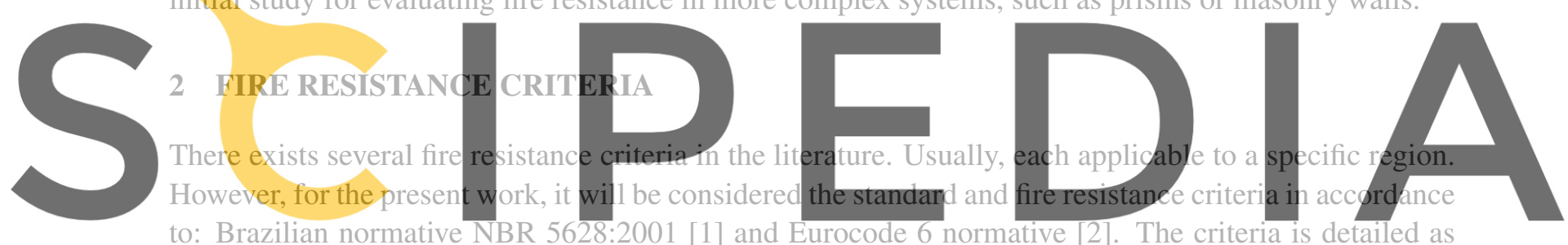

to: Brazilian normative NBR 5628:2001 [1] and Eurocode 6 normative [2]. The criteria is detailed as

Register follows: free at https//www.scipedia.com to download the version without the watermark

- Mechanical Resistance (R'). the structure does not attain rupture during fire exposure, performing its mechanical function at a time interval.

- Thermal behavior (T). Any point in the structure surface, not exposed to fire, should not exceed a temperature of $180^{\circ} \mathrm{C}$ and the mean temperature should not be greater than $140{ }^{\circ} \mathrm{C}$ above ambient temperature.

- Permeability (P). the constructive element capacity of preventing cracks or openings that allow fire or hot gases to pass across the structure.

\section{METHODOLOGY}

The numerical investigation was conducted using the FEM commercial software ABAQUS/CAE. Regarding the numerical model in ABAQUS, we used the Linear Solid Heat Transfer element DC3D8 for both, the prism and the air mass. Moreover, as all parameters are dependent on time, we used a transient analysis. 
For representing the fire conditions as a precise replication of the real conditions, we used the heating rate proposed in the ISO 834-1:1999 normative [4], which is specially used to account for a accurate fire representation.

Material properties such as thermal conductivity and specific heat are dependent on temperature, following the line of the precise replication of real conditions we intended to reach. It is worth to mention that these properties were obtained from literature [8].

The following heat transfer modes were considered:

- Face exposed to fire. The fire was represented by the standard ISO curve [4]. Convection and radiation were considered as the heat transfer modes from the fire to the face exposed to fire.

- Block interior. The air mass was simplified by considering it as a solid, in this manner, conduction was considered for the interior of the blocks.

- Face not exposed to fire. Convection and radiation was considered for the heat transfer mode between the face that is not exposed to fire and the ambient.

All geometries considered have a clear symmetry, which we took advantage in our numerical model. The symmetry allowed us to have the same accuracy using less computational effort. Allowing, at the same time, the possibility of using finer meshes. Thus, several block geometries were analyzed, as can be seen in Figure 1.

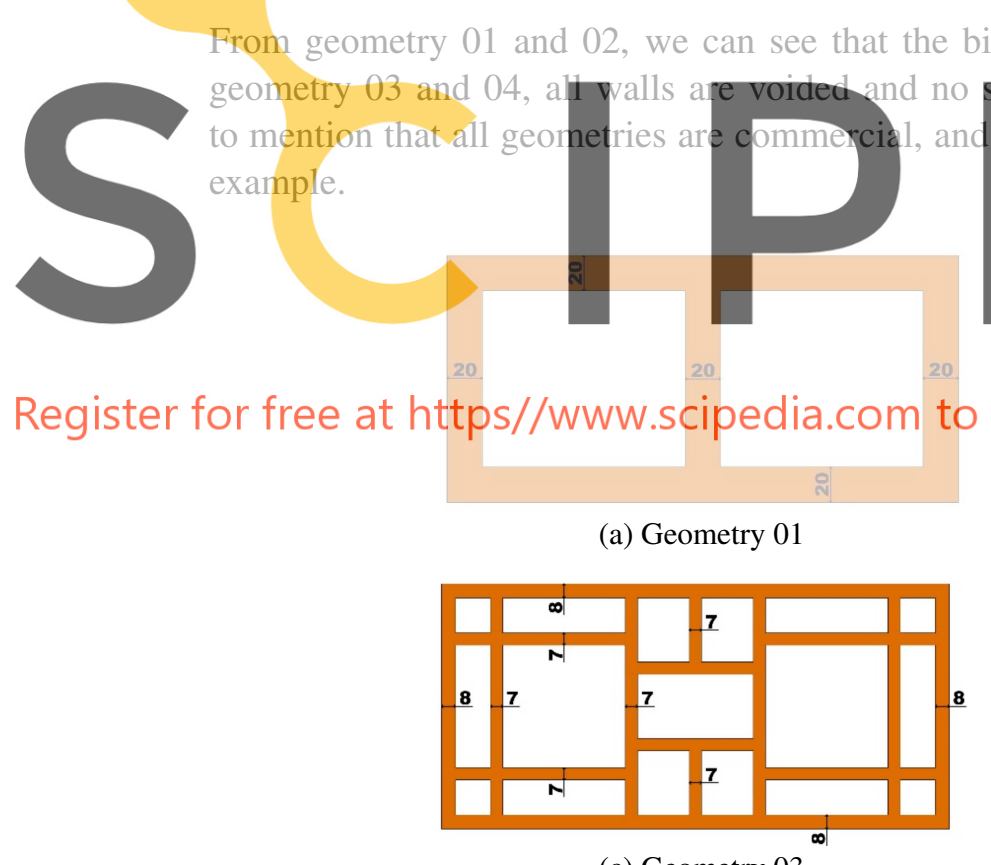

(c) Geometry 03

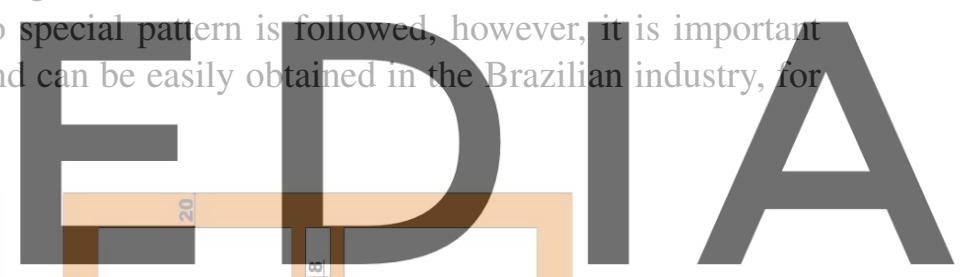

$8 \quad 8$ (b) Geometry 02

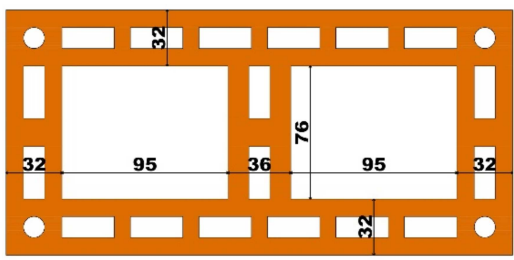

(d) Geometry 04

Figure 1: Block geometries considered for the numerical models. 


\section{RESULTS}

In order to properly evaluate the influence of the geometry in the thermal behaviour of the blocks, for each geometry was considered three cases: no coating, coating in one side (the side exposed to fire), and the case in which the coating is in both sides of the block. As a result the numerical study consists on twelve numerical models.

As mentioned before, symmetry was considered in order to have a more accurate result, as a consequence of the possibility of testing finer meshes. The symmetry plane is shown in Figure 2. Nodal points were considered in the exterior lateral plane and in the plane of symmetry, A and B, respectively. The total number of points depend on the geometry, and is, generally, different for each type of block.

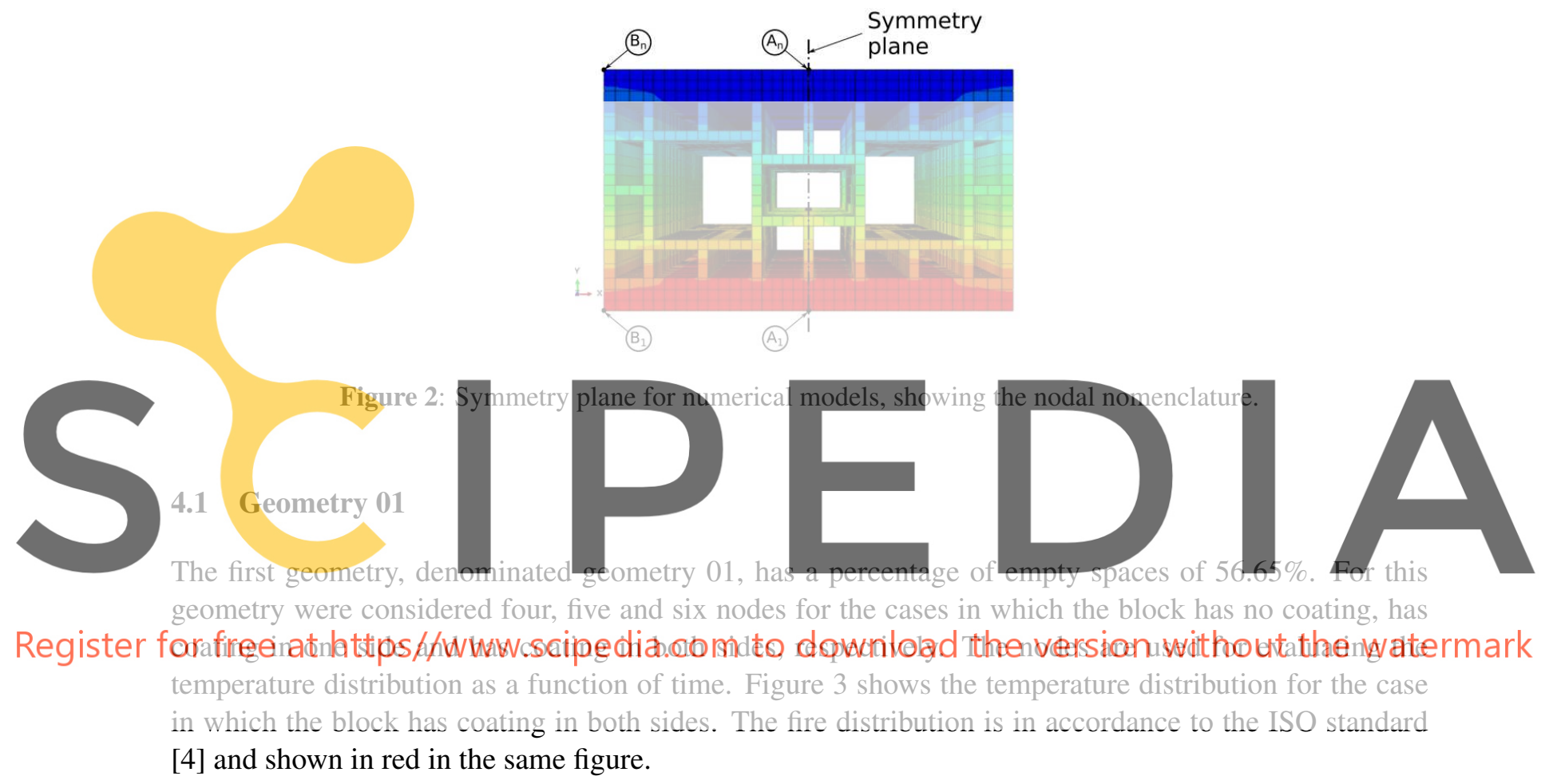




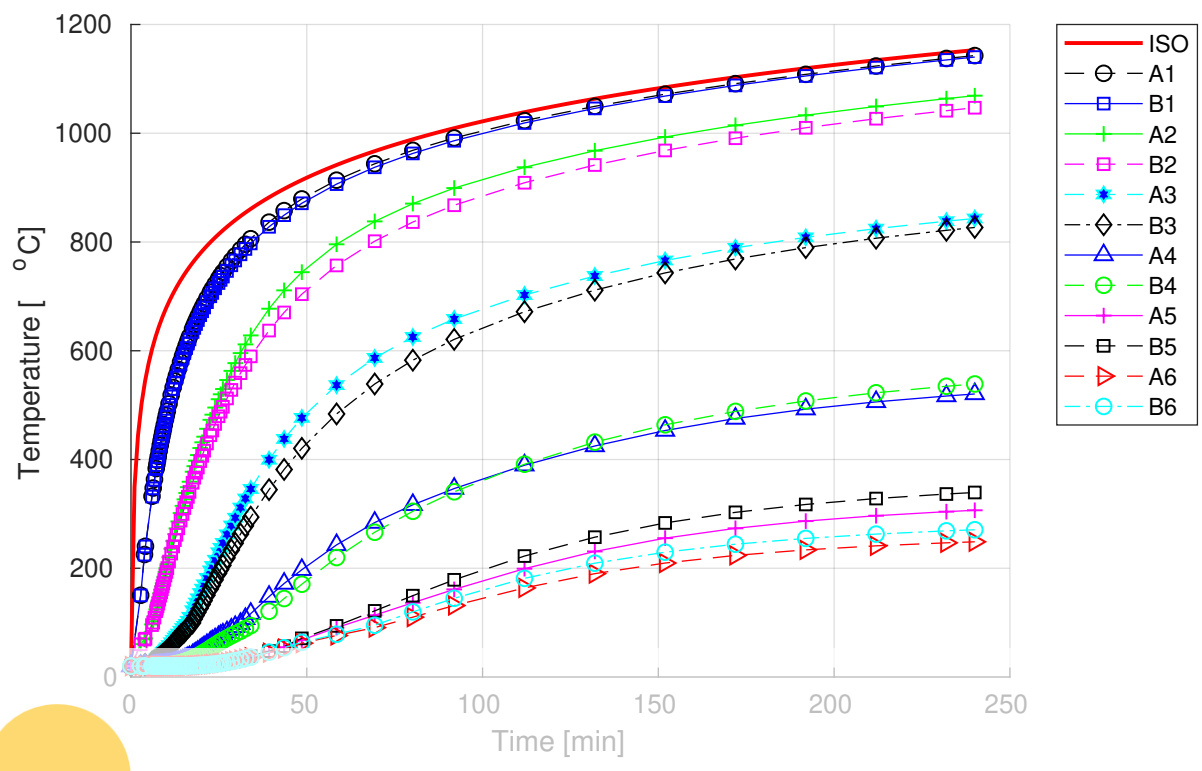

Figure 3: Temperature distribution as function of time for the geometry 01.

Nodal temperatures for the face that is not exposed to fire are also shown in Table 1.
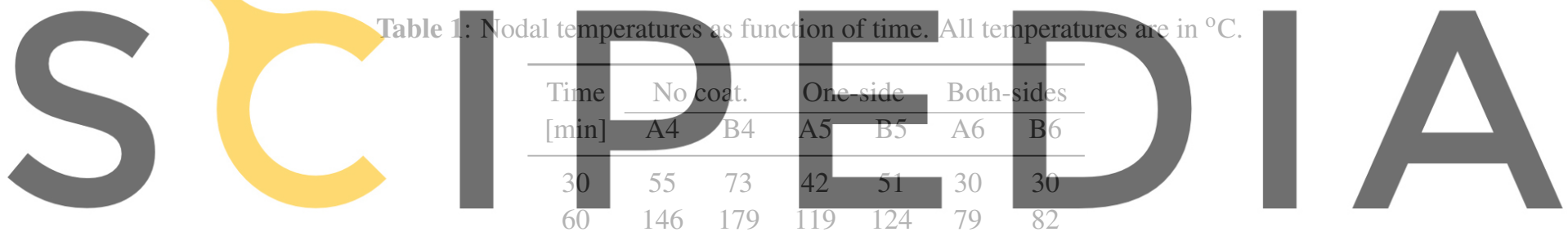

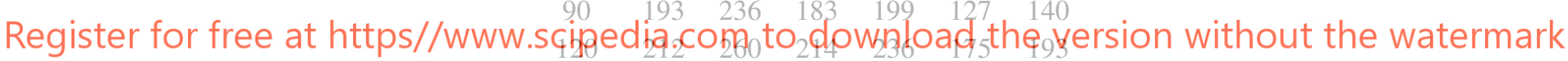

\begin{tabular}{lllllll}
180 & 228 & 280 & 236 & 264 & 228 & 248 \\
240 & 235 & 289 & 245 & 275 & 248 & 270 \\
\hline
\end{tabular}

For the case that we have no coating the temperature reached was $289^{\circ} \mathrm{C}$. When there was coating at one side the temperature reached was $275^{\circ} \mathrm{C}$, representing a reduction of $4.84 \%$ compared to the worst case, case in which there was no coating. Finally, in the case with coating on both sides the temperature reached was $270{ }^{\circ} \mathrm{C}$, representing a reduction of $6.57 \%$ compared to the worst case.

\subsection{Geometry 02}

The second geometry, denominated geometry 02 , has a percentage of empty spaces of $57.08 \%$. For this geometry were considered eight, nine and ten nodes for the cases in which the block has no coating, has coating in one side and has coating in both sides, respectively. The nodes are used for evaluating the temperature distribution as a function of time. Figure 4 shows the temperature distribution for the case 
in which the block has coating in both sides. The fire distribution is in accordance to the ISO standard [4] and shown in red in the same figure.

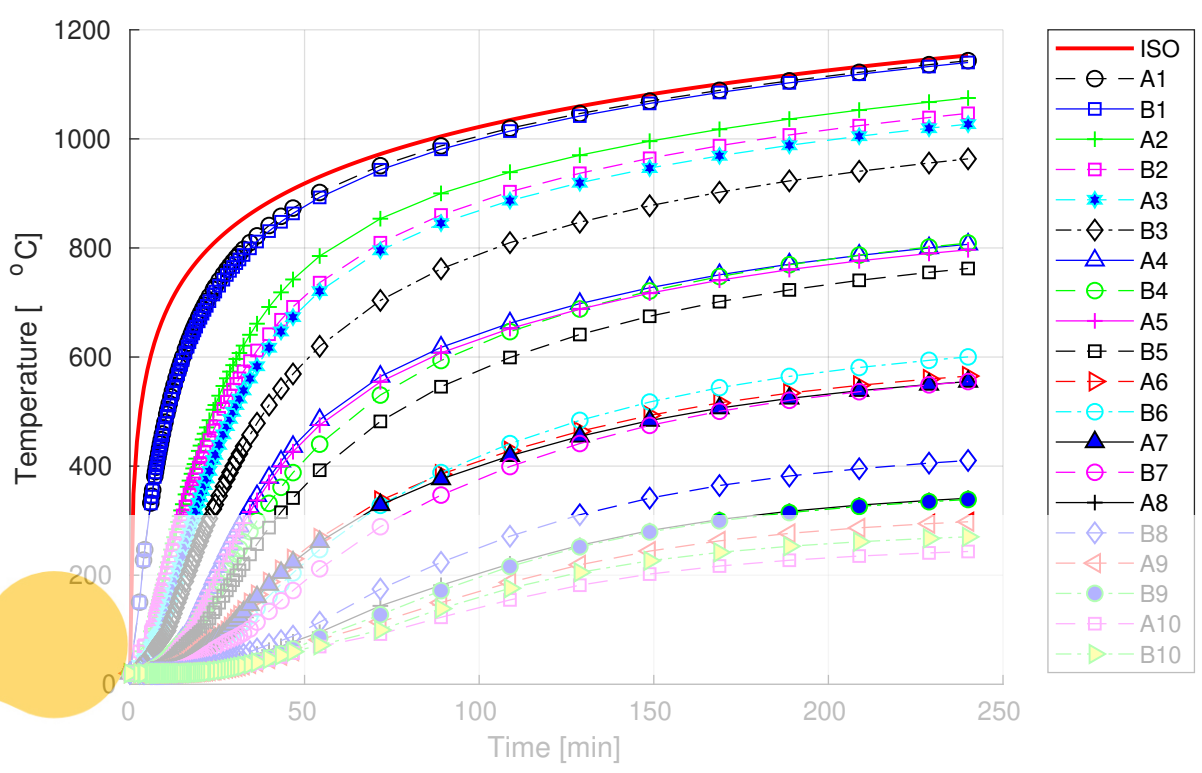

Figure 4: Temperature distribution as function of time for the geometry 02.

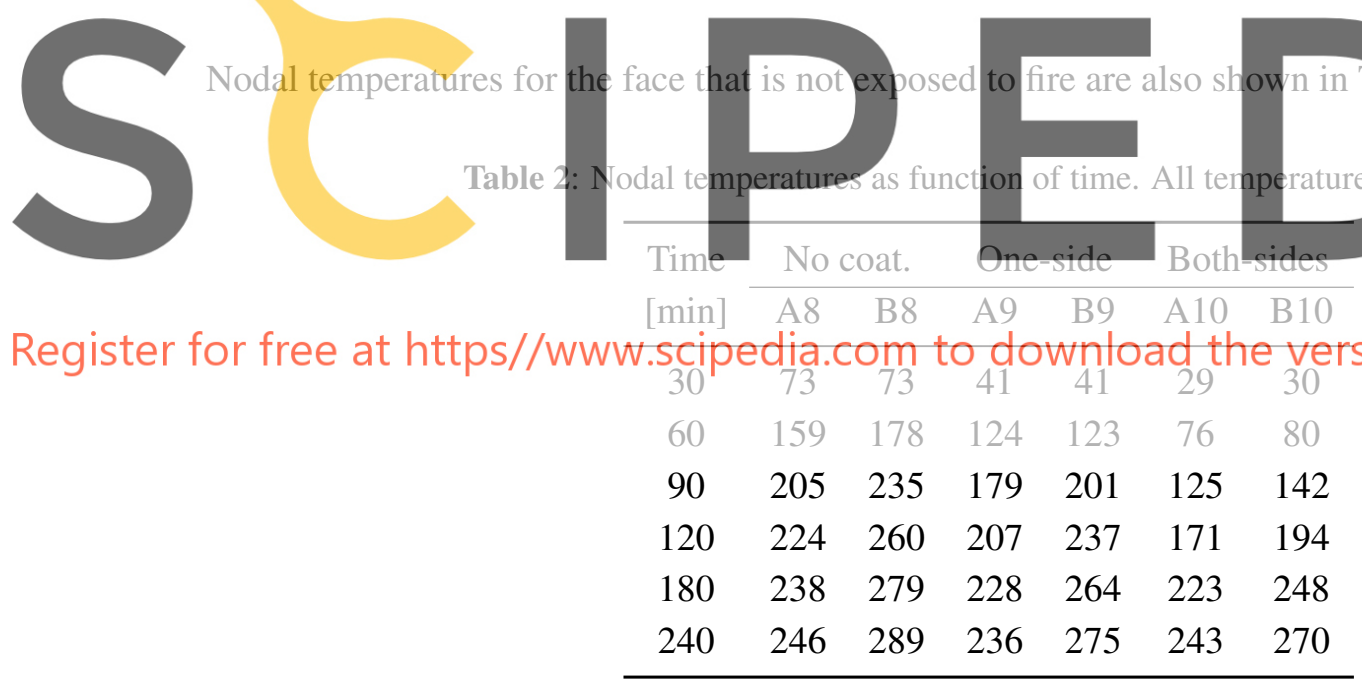

For the case that we have no coating the temperature reached was $289^{\circ} \mathrm{C}$. When there was coating at one side the temperature reached was $275^{\circ} \mathrm{C}$, representing a reduction of $4.84 \%$ compared to the worst case, case in which there was no coating. Finally, in the case with coating on both sides the temperature reached was $270{ }^{\circ} \mathrm{C}$, representing a reduction of $6.57 \%$ compared to the worst case. 


\subsection{Geometry 03}

The third geometry, denominated geometry 03 , has a percentage of empty spaces of $65.38 \%$. For this geometry were considered four, five and six nodes for the cases in which the block has no coating, has coating in one side and has coating in both sides, respectively. The nodes are used for evaluating the temperature distribution as a function of time. Figure 5 shows the temperature distribution for the case in which the block has coating in both sides. The fire distribution is in accordance to the ISO standard [4] and shown in red in the same figure.
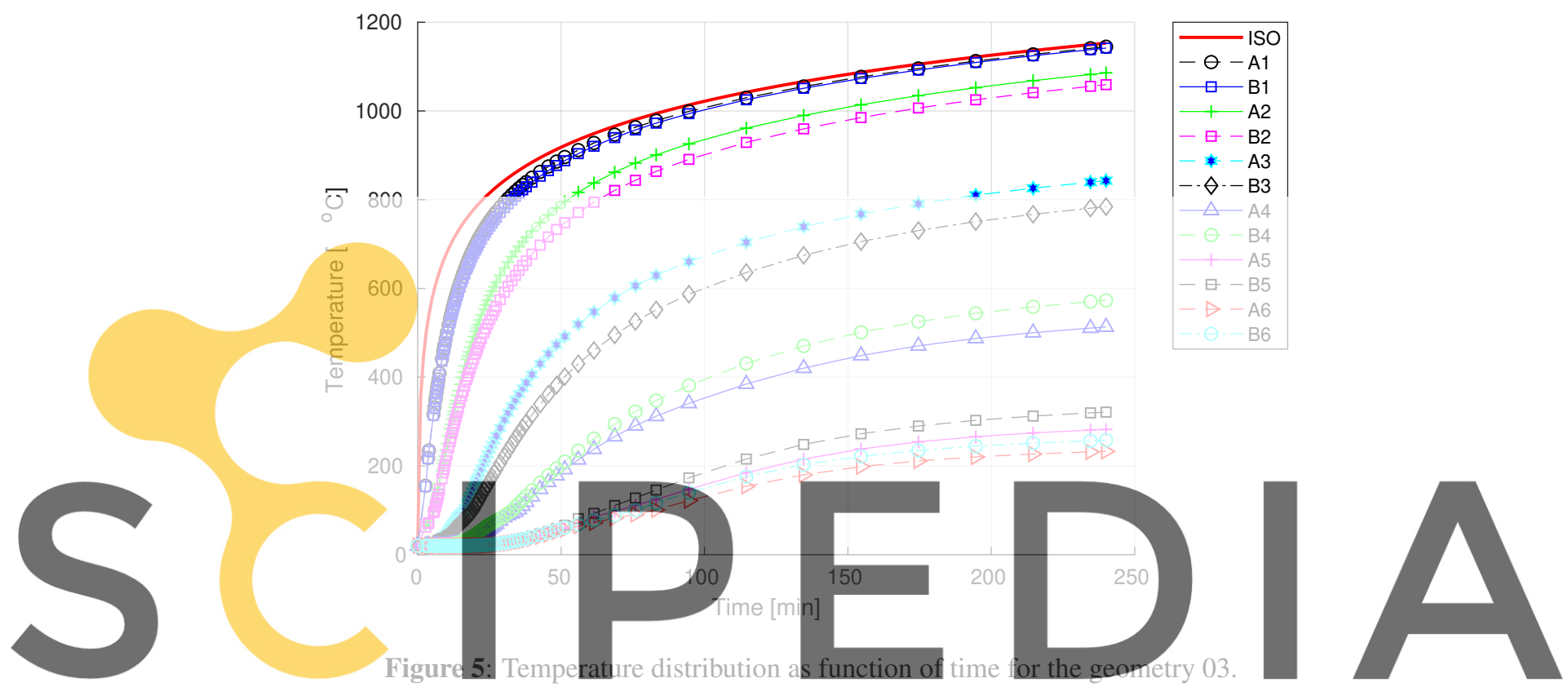

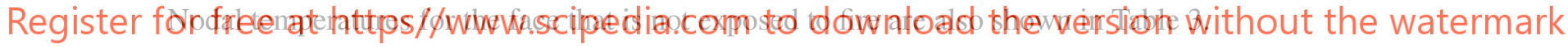

Table 3: Nodal temperatures as function of time. All temperatures are in ${ }^{\circ} \mathrm{C}$.

\begin{tabular}{ccccccc}
\hline \multirow{2}{*}{$\begin{array}{c}\text { Time } \\
\text { [min] }\end{array}$} & \multicolumn{2}{c}{ No coat. } & \multicolumn{2}{c}{ One-side } & \multicolumn{2}{c}{ Both-sides } \\
\cline { 2 - 7 } & A4 & B4 & A5 & B5 & A6 & B6 \\
\hline 30 & 56 & 63 & 32 & 35 & 24 & 26 \\
60 & 145 & 165 & 102 & 117 & 69 & 74 \\
90 & 189 & 220 & 165 & 189 & 114 & 132 \\
120 & 207 & 244 & 192 & 223 & 162 & 184 \\
180 & 221 & 262 & 212 & 249 & 214 & 238 \\
240 & 229 & 271 & 220 & 260 & 232 & 257 \\
\hline
\end{tabular}

For the case that we have no coating the temperature reached was $271{ }^{\circ} \mathrm{C}$. When there was coating at one side the temperature reached was $260^{\circ} \mathrm{C}$, representing a reduction of $4.06 \%$ compared to the worst 
case, case in which there was no coating. Finally, in the case with coating on both sides the temperature reached was $257{ }^{\circ} \mathrm{C}$, representing a reduction of $5.17 \%$ compared to the worst case.

\subsection{Geometry 04}

The forth geometry, denominated geometry 04 , has a percentage of empty spaces of $52.64 \%$. For this geometry were considered six, seven and eight nodes for the cases in which the block has no coating, has coating in one side and has coating in both sides, respectively. The nodes are used for evaluating the temperature distribution as a function of time. Figure 6 shows the temperature distribution for the case in which the block has coating in both sides. The fire distribution is in accordance to the ISO standard [4] and shown in red in the same figure.

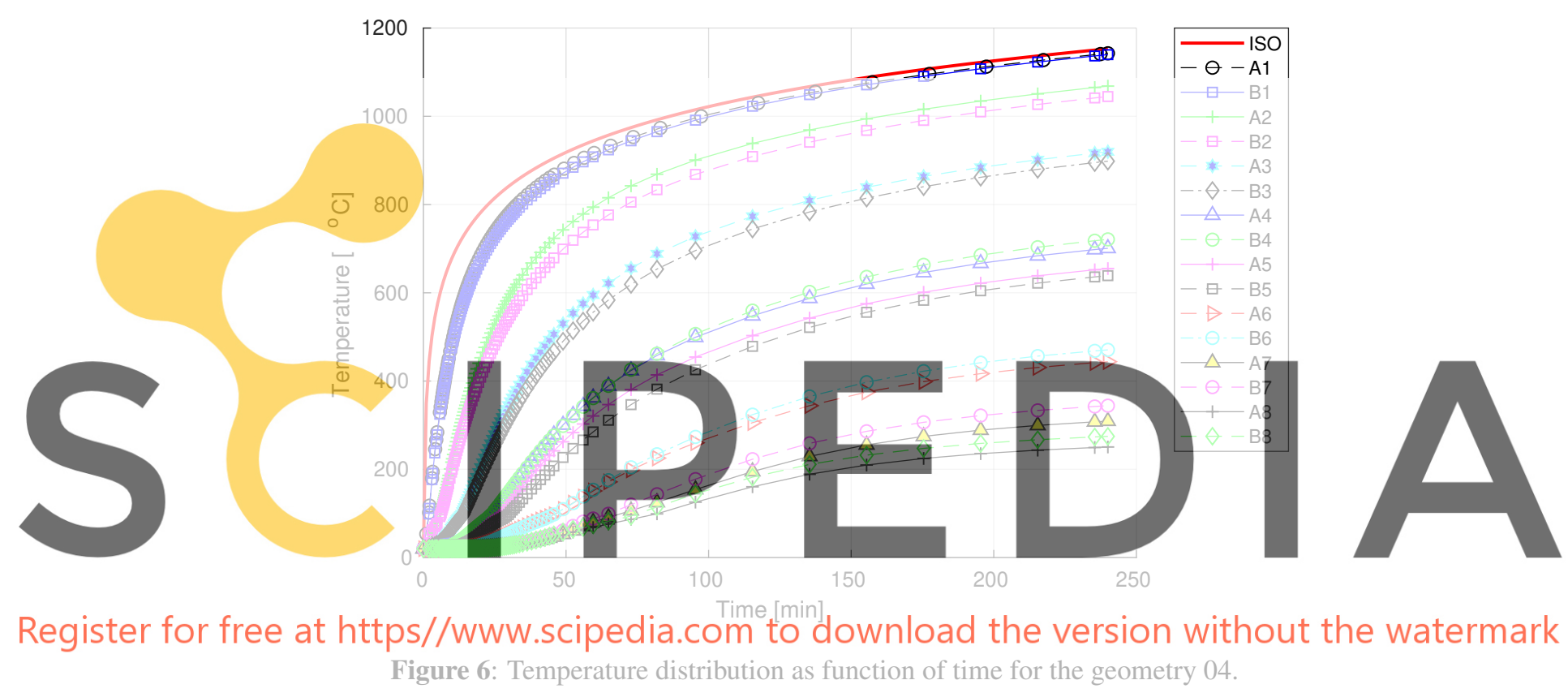

Nodal temperatures for the face that is not exposed to fire are also shown in Table 4.

Table 4: Nodal temperatures as function of time. All temperatures are in ${ }^{\circ} \mathrm{C}$.

\begin{tabular}{ccccccc}
\hline \multirow{2}{*}{$\begin{array}{c}\text { Time } \\
{[\mathrm{min}]}\end{array}$} & \multicolumn{2}{c}{ No coat. } & \multicolumn{2}{c}{ One-side } & \multicolumn{2}{c}{ Both-sides } \\
\cline { 2 - 7 } & A6 & B6 & A7 & B7 & A8 & B8 \\
\hline 30 & 56 & 63 & 32 & 35 & 24 & 26 \\
60 & 147 & 166 & 98 & 112 & 68 & 74 \\
90 & 203 & 231 & 172 & 193 & 115 & 133 \\
120 & 228 & 260 & 207 & 234 & 166 & 188 \\
180 & 247 & 283 & 234 & 266 & 227 & 249 \\
240 & 256 & 293 & 245 & 278 & 250 & 274 \\
\hline
\end{tabular}


For the case that we have no coating the temperature reached was $293{ }^{\circ} \mathrm{C}$. When there was coating at one side the temperature reached was $278{ }^{\circ} \mathrm{C}$, representing a reduction of $5.12 \%$ compared to the worst case, case in which there was no coating. Finally, in the case with coating on both sides the temperature reached was $274{ }^{\circ} \mathrm{C}$, representing a reduction of $6.48 \%$ compared to the worst case.

\section{CONCLUSIONS}

In the present work, the dependence on the thermal behavior was accounted using FEM and the commercial software ABAQUS. The block interior voids were simplified by considering them as solid elements with air properties, in that manner, conduction was considered for void representation. The following conclusions can be mentioned about block thermal response:

- The geometry 03 (voided walls) was the best in terms of thermal behaviour, due to the high percentage of empty spaces $(65.38 \%)$.

- The geometry 03 without coating represented a reduction of $11.07 \%$ in terms of temperature, compared to geometry 01 without coating.

- The geometry 04 was the worst in terms of thermal behaviour, this could be related to its low percentage of empty spaces $(52.64 \%)$.

Finally, The air mass plays an excellent insulating function, however, the overall result depends also on the percentage of empty spaces and their distribution along the block. Better results are expected if the voids are represented by

ally demanding. In this dealing with blocks at

REFERENCES
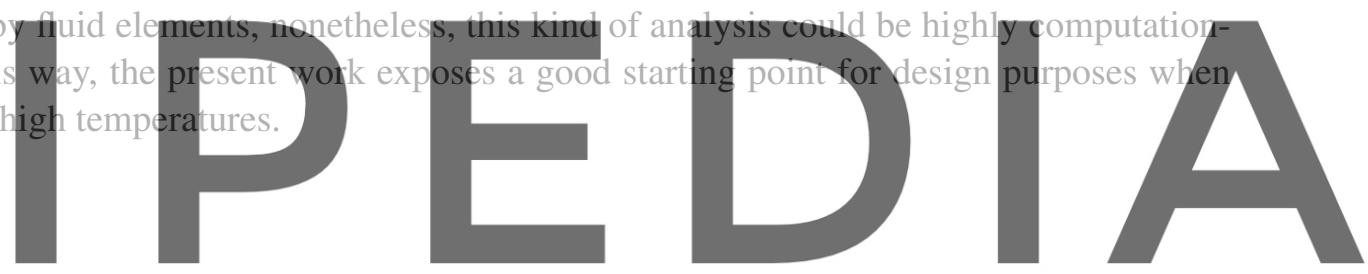

[1] A. ASSOCIAÇÃO BRASILEIRA DE NORMAS TÉCNICAS. NBR 5628: Componentes constru-

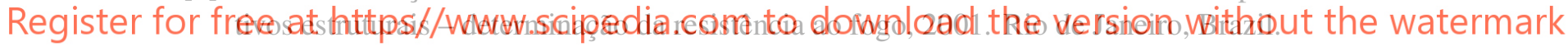

[2] European Committee for Standardization, Brussels. Eurocode 6: EN 1996-1.2: design of masonry structures: Part 1-2: general rules: structural fire design, 2005.

[3] Fire Safety Design - FSD. TCD 5.0 User's manual. Lund: Fire Safety Design AB, 2002.

[4] International Organization for Standardization, Geneve. ISO 834: Fire resistance tests - elements of building construction: part 1.1: general requirements, 1999.

[5] T. D. Nguyen and F. Meftah. Behavior of clay hollow-brick masonry walls during fire. part 1: Experimental analysis. Fire Safety Journal, 52:55-64, 2012.

[6] C. D. Pedgen, R. E. Shannon, and R. P. Sadowski. Introduction to simulation using SIMAN. McGraw-Hill College, New York, US, 1 edition, 1995.

[7] Polícia Militar do Estado de São Paulo, São Paulo: Secretaria de Estado dos Negócios da Segurança Pública. Corpo de Bombeiros. Instrução Técnica $n^{o}$ 02/2018: Conceitos básicos de segurança contra incêndio, 2018. 
[8] F. S. Rodovalho and M. R. S. Corrêa. Thermal simulation of prisms with concrete blocks in a fire situation. Ibracon Structures and Materials Journal, 12(3):638-657, 2019.

[9] S. Russo and F. Sciarretta. Experimental and theoretical investigation on masonry after high temperature exposure. Experimental Mechanics, 52(4):341-359, 2012.

[10] A. I. Seito, A. A. Gill, F. D. Pannoni, R. Ono, S. B. Silva, U. Del Carlo, and V. P. A. Silva. Segurança contra Incêndio no Brasil. Projeto Editora, São Paulo, 1 edition, 2008.
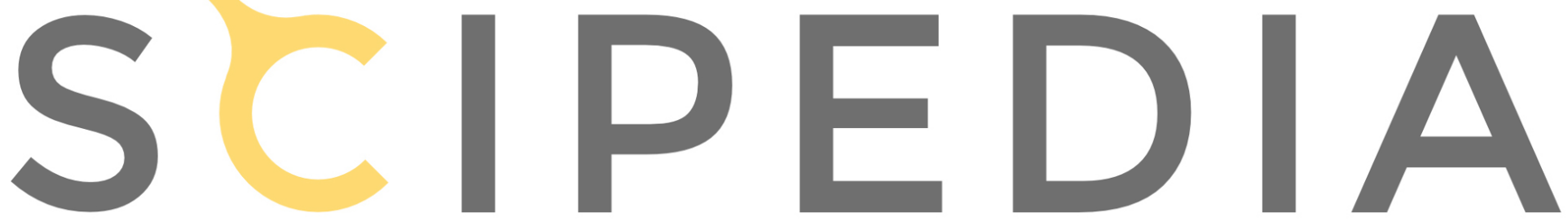

Register for free at https//www.scipedia.com to download the version without the watermark 